\title{
Conforto e lógica hospitalar: análise a partir da evolução histórica do conceito conforto na enfermagem
}

\author{
Fernanda Carneiro Mussi ${ }^{1}$ \\ Mussi FC. Conforto e lógica hospitalar: análise a partir da evolução histórica do conceito \\ conforto na enfermagem. Acta Paul Enferm 2005; 18(1):72-81. \\ RESUMO: A análise da literatura de Enfermagem evidencia que desde os primórdios da profis- \\ são até o presente, o conforto é uma meta do cuidado e um conceito presente em toda a sua \\ história. Assim, este estudo analisa concepções teóricas sobre conforto na história da enfer- \\ magem e seus determinantes, na tentativa de encontrar pistas para lançar luz nas imprecisões \\ teóricas existentes sobre conforto e nas contradições experienciadas na prática e ensino da \\ enfermagem no que se refere a promoção do conforto.
}

Descritores: Papel do profissional de enfermagem; Cuidados de enfermagem; História da enfermagem

- Artigo recebido em 14/07/04 e aprovado em 22/09/04

\section{INTRODUÇÃO}

A análise da literatura de Enfermagem evidencia que desde os primórdios da profissão até o presente, o conforto é uma meta do cuidado e um conceito presente em toda a sua história ${ }^{(1-2)}$. Todavia, o enfoque de conforto modifica-se ao longo dessa história e sofre influência de fatores religiosos, da racionalidade médico-científica, das exigências políticas e econômicas institucionais, entre outros.

A compreensão da origem e evolução das concepções atribuídas ao conforto e seus determinantes impõe a tarefa de revisar e analisar a história da enfermagem, bem como o arcabouço conceitual que a constitui como prática e discurso científico, pois a identidade e subjetividade dos profissionais de enfermagem não é algo inato, mas formado ao longo da história das práticas de enfermagem; estão vinculadas aos elementos conceituais implícitos ou explícitos nos modelos teóricos que, hoje, legitimam a enfermagem como profissão.

Assim, esse estudo, tem como objetivo analisar as concepções teóricas sobre conforto na história de enfermagem e seus determinantes, visando encontrar pistas para lançar luz nas imprecisões teóricas existentes sobre conforto e contradições experienciadas na prática e ensino da enfermagem no que se refere a promoção do conforto.

\section{EVOLUÇÃO DO \\ CONCEITO DE CONFORTO}

Nos primórdios, a enfermagem era uma obra de misericórdia para a salvação da alma. Desde o início da era cristã, constata-se que o conforto era sua meta:

O cuidado consistia em dar banho nos pacientes, especialmente naqueles que tinham doenças transmissíveis e estavam febris, fazer curativos, incluindo aplicação de compressas nas áreas queimadas, dar alimentos e dieta líquida e proporcionar conforto físico e espiritual a todo o paciente, especialmente ao moribundo ${ }^{(3)}$.

Na idade Média européia, os agentes da enfermagem eram pessoas ligadas à Igreja Católica Romana, cujas práticas eram desvinculadas das atividades médicas. A salvação de suas almas dependia da salvação da alma do doente, por meio do cuidado. Havia uma relação direta entre os agentes (enfermeiros) e os

\footnotetext{
${ }^{1}$ Doutora. Professora Adjunta I da Universidade Federal da Bahia. E-mail: femussi@uol.com.br
} 
doentes. O enfermeiro confortava mediado pelo modelo religioso ${ }^{(4)}$.

Do início do cristianismo até o feudalismo na Idade Média, temos uma enfermagem independente da prática médica, ou seja, suas ações não pressupunham ordens médicas ou planos médico-terapêuticos. Parece que eram dois trabalhos com objetos e objetivos diferentes e as técnicas significavam simples procedimentos caseiros, pois o objetivo do cuidado de enfermagem não se ligava ao corpo doente nem à sua doença: importava o conforto da alma do paciente para sua salvação e a dos agentes da enfermagem, portanto, sem necessidade de uma teoria do cuidado de enfermagem (grifo nosso) ${ }^{(4)}$.

Fica claro que a medicina e a enfermagem tiveram origens independentes, ambas seguindo trajetórias históricas próprias. Os mesmos autores acima, apoiados em Foucault, reafirmam a independência do trabalho de médicos e enfermeiros e brindam-nos uma retrospectiva histórica dos hospitais - espaço para onde, no futuro, iriam convergir ambas as práticas:

O hospital que funcionava na Europa desde a Idade Média não era, por nenhum conceito, um meio de cura, nem havia sido concebido para curar. Na história do cuidado do doente no Ocidente, houve, na realidade, duas classes distintas que não se superpunham, que às vezes se encontravam, mas que diferiam fundamentalmente, a saber: a médica e a hospitalar. [...] $\mathrm{O}$ hospital era essencialmente uma instituição de assistência aos pobres, mas, ao mesmo tempo, era uma instituição de separação e exclusão. O pobre, como tal, necessitava de assistência e, como enfermo, era portador de doença e possível propagador das mesmas. Em resumo, era perigoso. Daí a ne- cessidade da assistência no hospital, tanto para reconhecê-lo como para proteger os demais contra o perigo de que o paciente era portador. [...] Portanto, quem estava nos hospitais eram os pobres e o pessoal de enfermagem que cuidava desses doentes... ${ }^{(4)}$.

A crença na salvação da alma mediante o cuidado aos doentes parece permanecer até por volta de 1860, como esclarece Foucault :

o pessoal hospitalar não estava destinado a curar o enfermo, mas a conseguir sua própria salvação. Era um pessoal caritativo (laico e religioso), que estava no hospital para fazer obras de misericórdia que lhe garantiam a salvação eterna ${ }^{(5)}$.

Por meio de simples técnicas de cuidados relacionados à alimentação, ao preparo de chás, à lavagem de roupas e feridas, à higiene pessoal e ambiental do paciente, obtinham "o conforto da alma do doente" e, com ele, a própria salvação.

A grande mudança da finalidade do hospital, lugar onde se ia para morrer, sem objetivo de cura e destinado à separação e exclusão do pobre e doente, se dá no século XVII, nos hospitais marítimos e militares, por influência do mercantilismo, etapa anterior ao capitalismo. O fervilhar das atividades portuárias e das guerras, a intensificação do tráfego de bens e pessoas provocam desordens nesses ambientes, tornando-os focos potenciais de epidemias, que poderiam se propagar causando grandes prejuízos. O novo hospital surge como uma instituição disciplinadora desse ambiente caótico. É uma resposta às demandas de uma nova ordem econômica:

O capitalismo que se instalava no século XVIII ia necessitar do corpo como força de trabalho e cabia à medicina sua manutenção e restauração ${ }^{(4)}$.
A disciplina militar foi fundamental para dar essa nova face aos hospitais:

A partir da transformação técnica do exército, em fins do século XVII, o hospital militar converteu-se em uma questão técnica e militar importante. [...] A reordenação destes hospitais não partiu de uma técnica médica, mas sim, essencialmente, de uma tecnologia que poderia denominar-se política: a disciplina. [...] A introdução dos mecanismos disciplinares no espaço confuso do hospital permitiu sua medicalização ${ }^{(5)}$.

A nova concepção dos hospitais é também influenciada por objetivos médicos: coordenar cuidados, vigiar e separar os doentes, impedindo os contágios. A partir do momento em que o hospital é organizado como local de cura, o pessoal religioso e leigo que realizava as tarefas hospitalares passou a trabalhar com um novo membro na hierarquia e disciplina hospitalar: o médico.

As duas práticas, a médica e a de enfermagem, que eram independentes, encontram-se agora no mesmo espaço geográfico, o espaço hospitalar, e no mesmo espaço social, o do doente ${ }^{(4)}$.

Mas se essa disciplina adquire caráter médico, se esse poder disciplinar se confia ao médico, isso se deve também a uma transformação do saber médico. [...] A perspectiva de cura encaminha-se um pouco à margem da doença e do organismo, orienta-se para o meio que o rodeia: o ar, a água, a temperatura ambiente, a dieta, a alimentação e outros. É uma medicina do meio que se está constituindo, na medida em que a doença é concebida como um fenômeno natural que obedece a leis naturais. 
Com essas transformações, o hospital também passou a ser um local de formação e aprimoramento científico ${ }^{(6)}$. Com base em Foucault, 1978, as razões por trás da medicalização do hospital e do surgimento do indivíduo como novo objeto da prática médica são enfatizadas no estudo:

O deslocamento da intervenção médica para o hospital e a aplicação de disciplina nesse novo ambiente são a origem do hospital médico [...] Portanto, o saber médico, que até o século XVIII estava localizado nos livros, em uma espécie de jurisprudência médica concentrada nos grandes tratados clássicos de medicina, começa a ocupar um lugar, não nos textos, senão no hospital. [...] Com a aplicação da disciplina do espaço médico e pelo fato de que se pode isolar cada indivíduo, instalá-lo em uma cama, prescrever-lhe uma dieta, etc., pretende-se chegar a uma medicina individualizante. Com efeito, é o indivíduo que será observado, vigiado, conhecido, curado. $\mathrm{O}$ indivíduo surge como objeto do saber e da prática médica ${ }^{(4)}$.

Quando os hospitais e os indivíduos se tornam objeto da prática médica, também surgem mudanças na concepção de conforto. Aos poucos, o médico vai se concentrando cada vez menos no estudo do ambiente e deslocando suas atenções para o estudo do corpo, deixando o ambiente a cargo das enfermeiras:

Começa a se construir a teoria do objeto da medicina voltada para o corpo. Enquanto o saber da medicina vai passando do meio ambiente para o doente, a enfermagem centra-se no seu ambiente [...] O modelo religioso do cuidado de enfermagem vai sendo aos poucos substituído por um cuidado do ambiente físico do paciente, para dar condições para a nature- za agir no corpo do paciente [...] Não só o ambiente físico do hospital passa a ser objeto de disciplinamento, como também o pessoal de enfermagem, pois o cuidado era realizado por mulheres decadentes, necessitando, portanto, de disciplinamento ${ }^{(4)}$.

Configura-se, assim, a nova função do enfermeiro no hospital:

Mas além do cuidado do ambiente do paciente, era necessário executar as ordens médicas dirigidas à cura do doente e foi o pessoal de enfermagem que desempenhou essa função. [...]A institucionalização da enfermagem surge com a finalidade principal de disciplinar a conduta do pessoal que trabalhava nos hospitais e executar o modelo disciplinar do espaço do doente - ventilação, água, higiene e outros ${ }^{(4)}$.

A subordinação da enfermagem à ordem médica é ilustrada por Shaw, contemporânea de Nightingale, que descreveu as tarefas da enfermeira: do ponto de vista da própria enfermeira, a visão é altruísta, devendo esta assumir a missão de ajudar o próximo; para com o médico, suas tarefas são as de levar a efeito as diretrizes prescritas; e, para com os pacientes, ela deve fazer tudo o que for de efetivo para sua saúde e conforto, antecipando até suas vontades ${ }^{(7)}$. A concepção das atividades de enfermagem expressa por Shaw, naquela época, permite entrever a subordinação do trabalho de enfermagem ao trabalho médico, assim como o reforço à noção do conforto como objetivo dessa atividade. Todavia, parece que a enfermagem vai perdendo a antiga autonomia para a promoção do conforto. Como as ordens terapêuticas médicas deviam ser executadas, a provisão do conforto passa a ser influenciada e subordinada a elas. Além disso, o enfoque do conforto da alma do paciente se desloca para a modificação de seu ambiente.
O modelo religioso de enfermagem emerge no mundo cristão, atravessa a Idade Média e vai-se defrontar com o capitalismo na Inglaterra, no final do século XVIII e início do século XIX, e com a ascensão da burguesia e sua instalação como classe social dominante, que dará o significado de arte ou vocação à prática da enfermagem para tornar possível o treinamento de alguns agentes. Portanto, no capitalismo o modelo religioso é substituído pelo vocacional, um chamado para o trabalho que requer auto-sacrifício ${ }^{(4)}$.

Depreendem-se daí os primórdios da idéia altruísta do enfermeiro, evidenciada tanto no modelo religioso como no vocacional.

\section{$O$ conforto no século $X X$ na Enfermagem científica}

A revisão mais extensa sobre o tema conforto ao longo do século XX foi realizada por McIlveenn e Morse ${ }^{(1)}$. Em estudo pioneiro, as autoras assinalam o foco atribuído ao conforto, baseadas na análise da literatura clínica norte-americana de 1900 a 1980, demarcando três períodos: 1900-1929, 1930-1959 e 1960-1980. Convém ressaltar que, apesar dessa análise se concentrar na literatura norte-americana, sua extrapolação para nossa realidade é possível, pelo fato de a enfermagem brasileira ter sido influenciada pelos modelos daquele país, principalmente nas primeiras décadas do século $\mathrm{XX}$.

No período de 1900 a 1929, a maioria das enfermeiras ${ }^{a}$ norte-ame-

\footnotetext{
a Para a redação desta parte, vali-me de literatura em língua inglesa que, como é sabido, não tem formas diferentes para o masculino e o feminino (nurse). No entanto, como se podia inferir que as autoras referem-se basicamente a mulheres, optei pelo uso da forma feminina nesta passagem.
} 
ricanas eram contratadas pelos pacientes ou seus familiares para atuar no domicílio. Uma boa enfermeira era aquela que tornava o paciente confortável, e a provisão do conforto, especialmente à noite, quando estava sozinha, testava sua vocação como enfermeira. Se ela era capaz de confortar, era recontratada ou recomendada a outros pacientes. Portanto, naquela época, o conforto era a meta central e um imperativo moral da enfermagem. As ações de conforto eram essencialmente físicas: posicionamento com travesseiros, talas, coxins, almofadas ou sacos de areia, compressas com álcool, banhos terapêuticos para dor, massagens, inalações com vinagre/sal para náusea, enemas e cuidados com a pele. Devido ao controle das prescrições médicas e ao segredo que cercava o diagnóstico, bem como à distância social entre a enfermeira e o paciente, essa estava proibida de discutir a condição do doente. Por esse motivo, o conforto emocional, que poderia ser oferecido pelas habilidades de falar e ouvir, foi categorizado nos livros didáticos como conforto mental. Esse era alcançado, principalmente, pela provisão de conforto físico e modificação do ambiente. Entre as estratégias de conforto mental incluíam-se divertir o paciente, apurar com tato a causa de sua preocupação e referi-la às autoridades do hospital, incutir esperança e confiança ao paciente. A enfermeira devia, ainda, evitar discutir na presença do paciente a sua condição e demonstrar um desejo sincero de ajuda, crença na recuperação e uma atitude de silêncio simpática. Apesar da prática da enfermagem ocorrer nos lares, havia poucas referências do envolvimento da família na provisão do conforto ou da enfermeira como provedora de conforto à unidade familiar ${ }^{(1)}$.

O segundo período, de 1930 a 1959, é marcado por uma fase inicial de desemprego durante a depres- são econômica, e pela subseqüente falta de profissionais durante a guerra. A institucionalização das práticas de saúde aumentou o controle médico sobre o sistema hospitalar, aumentando pois a necessidade de subordinados complacentes para conduzir suas ordens. A fonte primária de emprego das enfermeiras mudou do domicílio para as instituições de saúde e passou a ser controlada pelos médicos - não mais pela relação direta das enfermeiras com os familiares dos pacientes. A inclusão de assistentes de enfermeiras e trabalhadores auxiliares tornou-se comum nos hospitais, à medida que as atividades de enfermagem foram sendo diferenciadas em funções hierárquicas, descritas como simples, intermediárias e complexas, ou básicas e técnicas. Desse modo, a enfermeira registrada passou a agir como supervisora e delegadora das tarefas de enfermagem, deixando de ser a provedora primária de conforto, afastando-se, assim, da relação direta com o paciente.

A introdução de múltiplas estratégias para a cura do paciente resultou, algumas vezes, na subordinação do conforto do paciente às metas médicas. Por exemplo, a prevenção de deformidade ou tensão sobre a linha de sutura foi considerada tão importante que era esperado submeter o paciente a dor e ao desconforto, em vez de adotar posições supostamente errôneas, mas mais confortáveis. O número de tratamentos e procedimentos de enfermagem relacionados à dor diminuiu, e o uso de analgésicos e narcóticos tornouse o recurso inicial para seu alívio. Conseqüentemente, o alívio da dor passou a ser mencionado na literatura, com maior freqüência, em detrimento do alcance do conforto.

O conforto deixa de ser a meta final e absoluta da enfermagem, tornando-se uma meta relativa ou uma estratégia para sua promoção.
O conforto emocional continuou a ser alcançado em conseqüência da atenção dispensada ao físico: higiene pessoal, lençóis alisados, travesseiros de tamanhos apropriados, ambiente limpo, iluminado e livre de ar encanado. Somente mais tarde, nesse período, as enfermeiras foram encorajadas a ouvir e dar explicações simplificadas às questões dos pacientes sobre procedimentos. Detalhes de conforto tais como posicionar um travesseiro ou fazer massagens eram considerados, algumas vezes, atenção extra e tornaram-se dependentes da disponibilidade de tempo da enfermeira. Ainda nesse período, a falha das enfermeiras na provisão de conforto era considerada responsabilidade do paciente. Por exemplo, as complicações decorrentes da recusa para respirar profundamente e tossir, ou lamentações contínuas de dor, eram faltas dos pacientes ${ }^{(1)}$.

No último período, 1960 a 1980, a expansão tecnológica trouxe grandes mudanças às atividades conduzidas pela enfermeira. Ela passou a dispor de pouco tempo para estar em contato direto com os pacientes, pois tinha de olhar para monitores, ministrar medicações e supervisionar a equipe e as estudantes de Enfermagem. Conseqüentemente, as ações denominadas "simples", como as medidas de conforto físico, passam a ser executadas por membros da equipe de enfermagem ou pela família. No ensino de Enfermagem, a noção de conforto continuou a mudar, em virtude da introdução formal e adoção de perspectivas teóricas oriundas, principalmente, de outras disciplinas. Aliás, mudou o próprio ensino, com o lento processo de transferência do controle dos programas ou currículos dos hospitais para as instituições educacionais. O currículo, baseado nas artes liberais, passou a incluir cursos de Psicologia e Enfermagem Psiquiátrica, contribuindo para o desejo de articular uma base teórica para a disciplina o que, por sua vez, teria forne- 
cido às enfermeiras uma fundamentação mais ampla para a prática, ao promover o desenvolvimento de aspectos psicossociais da assistência, o reconhecimento do valor da relação enfermeira-paciente. O conforto tornou-se, mais do que nos períodos anteriores, uma meta ou estratégia de menor importância para a enfermagem ${ }^{(1)}$.

Essa mudança de enfoque fez com que o conforto fosse classificado em termos de estruturas teóricas, sob outras metas ou conceitos. $\mathrm{O}$ conforto emocional passou a ser discutido com maior freqüência, mas continuou a ser pensado, predominantemente, do ponto de vista físico. A provisão de conforto físico e, essencialmente, o alívio da dor, são vistos como pré-requisito para a obtenção de outras metas da enfermagem, como o alívio da ansiedade da família. Algumas enfermeiras continuaram a escrever que o conforto e a ação dos analgésicos poderiam e deveriam ser aumentadas por meio da provisão de práticas relacionadas à esfera física, como cuidados com a boca, atenção a áreas de pressão, ambiente silencioso e, também, por intervenções não-físicas, como escuta, empatia, confiança, simpatia e diversão.

A enfermeira dependia do médico para o uso de novos equipamentos, para decidir sobre manter ou descontinuar procedimentos que afetavam o conforto físico, criar oportunidades de prover conforto emocional, ao esclarecer dúvidas a respeito do diagnóstico manifestadas pelo paciente, sem ser evasiva. Inevitavelmente, algumas das atividades de enfermagem e terapias médicas produziam desconforto e era permitido à enfermeira encorajar e persuadir o paciente a tolerar o desconforto físico para obter o bem-estar. Não se esperava que a enfermeira simplesmente consolasse o paciente com uma conversa divertida. Ela deveria direcionar a discussão sobre a condição do paciente, um assunto proibido nas fases iniciais da profissão. O uso de habilidades interpessoais e de comunicação, como ouvir, refletir e acolher a expressão de sentimentos, passou a integrar o processo de conforto ${ }^{(1)}$.

Essa nova atitude interativa com o paciente parece refletir um envolvimento dos pacientes com seu próprio conforto, caracterizando uma mudança em comparação ao período anterior, quando se esperava que as enfermeiras assumissem a responsabilidade total pelo conforto físico ou emocional dos pacientes. Visitas do clero e a permanência dos membros da família foram encorajadas pelas enfermeiras para confortar os pacientes. Embora elas reconhecessem que o conforto oferecido pela família era importante para o paciente, nem sempre era fácil possibilitar sua presença, devido a proibições médicas e regulamentos institucionais. A família torna-se também cliente da enfermagem e deve ser confortada.

A ligação do conforto, especialmente emocional, com a idéia de fortalecimento do paciente está presente nos três períodos. Explicitamente, no primeiro e início do segundo período foi assegurado que, mantendo-se os pacientes confortáveis física e mentalmente, estes teriam melhores condições de se beneficiar das terapias médicas.

Em suas conclusões, as autoras indicam que pode existir relação entre as palavras conforto, confiança e apoio e sugerem às enfermeiras que explorem a possível associação entre elas. Tendo observado que o uso desses termos aumentou entre 1960 e 1980, elas aventam a hipótese de que tenham sido usados como substitutos de conforto, graças às contribuições teóricas de outras ciências. O conforto atravessou o século sendo reconhecido como a principal meta da enfermagem somente quando a tecnologia médica falhava ou não estava disponível para o tratamento dos pacientes ${ }^{(1)}$.

\section{CONFORTO E LÓGICAHOSPITALAR}

A retrospectiva apresentada evidencia que o conforto está à mercê de fatores econômicos, políticos e ideológicos que desviam o enfermeiro da sua principal finalidade: promover o conforto dos pacientes.

Vimos que no primeiro período da história clínica norte-americana (1900-1929), o paciente permanecia no ambiente familiar e lá recebia atendimento médico e de enfermagem, enquanto, no segundo (19301959), era internado e submetido à norma da instituição médico-hospitalar. Nesse último caso, o paciente enfrenta uma ruptura com o cotidiano, determinada pela doença e agravada pela hospitalização e submissão aos desdobramentos dela decorrentes. O paciente passa a ser enquadrado nas normas e rotinas hospitalares (horários rígidos, refeições controladas, procedimentos de higiene etc.). Além disso, começa a viver um regime de tratamento que, via de regra, o impede de decidir e agir segundo sua própria determinação. Dentre os inúmeros desdobramentos da ruptura com a vida cotidiana, podemos citar o afastamento das atividades profissionais, a redução do grau de intimidade com pessoas que são importantes e a interrupção, mesmo que momentânea, dos projetos pessoais e profissionais.

Determinante para a institucionalização do conforto foi a mudança nas relações profissionais entre enfermeiros e pacientes. Vimos que, durante o primeiro período (19001929), a maioria das enfermeiras eram profissionais autônomas, prestadoras de serviços à família do paciente, nos hospitais ou domicílios. O colapso da economia americana impossibilitou que essas profissionais continuassem trabalhando nos moldes anteriores, pois os pacientes não tinham mais condições financeiras para remunerá-las. Isso, aliado a outros fatores, fez com que 
as enfermeiras, que antes exerciam suas funções em caráter privado, passassem a prestar serviços às instituições hospitalares e a ter uma relação trabalhista mediada por um contrato social, que determina uma rígida divisão hierárquica de funções:

O trabalho de enfermagem é todo subdividido e realizado em tarefas e procedimentos, sem centrar-se no paciente, ou seja, um mesmo paciente é assistido por vários elementos da enfermagem, um o auxilia na higiene pessoal, o outro lhe dá medicação, um outro faz curativo etc ${ }^{(4)}$.

Nessa nova fase, os procedimentos de enfermagem (organizados na Inglaterra no final do século XIX e implementados nos Estados Unidos, nas primeiras décadas desse século), que sempre estiveram presentes em outros momentos históricos como simples rituais de cuidado, cuja finalidade era o conforto da alma do paciente, eram agora atrelados a um novo contexto, dominado pela norma médica.

As novas relações de trabalho surgidas após a crise de 1929 remodelaram a prática da enfermagem, cuja principal finalidade passou a ser a promoção do conforto a partir das demandas médico-científicas, dos princípios de administração hospitalar e da nova racionalidade econômica, baseada nos pressupostos da gerência científica de Taylor:

Os instrumentos e técnicas de enfermagem, como foram concebidos nas primeiras décadas deste século, com a atenção voltada não para o doente, mas para o procedimento a ser executado, e viabilizando o controle social dos auxiliares, possibilitaram uma prática de enfermagem que foi denominada de modalidade funcional. Essa perdurou nas primeiras décadas do século nos Estados Unidos, mas ainda se encontra presente na en- fermagem brasileira. O foco da atenção da enfermagem, nessa modalidade, são as tarefas e os procedimentos. Há um princípio de reconhecimento de divisão de trabalho, com maior ênfase nos cuidados a serem prestados ao paciente, sendo que estes são agrupados para fins de economia e tempo e de maior presteza na execução do serviço [...] Essa modalidade resulta num trabalho do tipo produção em massa, sendo que a identidade do paciente se perde na lista de obrigações a serem cumpridas $[\ldots]^{(4)}$.

O período de 1932 a 1946 foi marcado pela proletarização da enfermagem $^{(8)}$. O crescente número de internações devido ao aumento do número de hospitais e ao maior fluxo de pacientes com menor tempo de internação desencadeou o emprego de um grande número de pessoal de enfermagem sem preparo, necessitando, portanto, de simples instrução sobre a maneira de executar os procedimentos, mas sem aprender o porquê deles.

O crescimento da demanda de serviços médico-hospitalares e a inserção dos enfermeiros nos hospitais foram acelerados com o surgimento dos seguros-saúde, os quais ajudaram a popularizar o atendimento à saúde e objetivaram, também, a recuperação econômica dos hospitais norte-americanos:

A Blue Cross e Blue Shields possibilitaram cuidados de saúde hospitalares para um grande segmento da população. Coincidindo com a criação do segurosaúde, houve a ampliação do nível de perícia técnica nos hospitais, surgimento de drogas, técnicas cirúrgicas, técnica de raio $\mathrm{X}$, medicina nuclear, terapêutica respiratória e outras. O hospital ganhou prestígio como instituição de cura e usou de todos os meios para desenvolver métodos de re- crutamento, organização e disciplinamento do staff de enfermagem para ganhar estabilidade como instituição ${ }^{(8)}$.

É também nos hospitais americanos que a técnica de enfermagem começa a se organizar como meio de trabalho, não tanto para as ações dos enfermeiros, mas para atender à grande demanda de seus serviços ${ }^{(4)}$. Sendo a promoção do conforto e da segurança do paciente as mais importantes finalidades da técnica de enfermagem naquela época, há de se questionar se, de fato, esta realmente oferecia conforto. A rigidez do horário de execução dessas técnicas e a divisão do trabalho dos enfermeiros poderiam impossibilitar o reconhecimento das necessidades do paciente.

A institucionalização das práticas de saúde gerou um desvio fundamental do papel do enfermeiro na promoção do conforto, reforçando a fragmentação de sua relação com o paciente, pois...

[... ] insere o médico com o papel claramente definido de curar, pautado na relação dual profissionalpaciente; [...] [a enfermagem é inserida] como profissão responsável pela disciplina do serviço de prática da saúde, visando dar sustentação às demandas médicas, tendo sua atuação pautada no controle do ambiente - iluminação, higienização e aeração; no controle das pessoas, de tempos e movimentos, estabelecendo local, horário e ritmo de trabalho; e no controle do processo de formação, determinando padrões de conduta moral e atuação profissional ${ }^{(9)}$.

Assim, houve uma apropriação das demandas que eram psíquicas, dos provedores de cuidados (de exercer caridade para a salvação própria), para atender às demandas sociais e institucionais. A necessidade de cuidar foi minimizada por funções 
técnicas, burocráticas e administrativas que apenas tangenciam o cuidar, determinando um desvio primordial do papel do enfermeiro que se estende até os dias de hoje ${ }^{(9)}$.

O distanciamento do doente resulta na quebra do contrato simbólico inicial estabelecido entre o enfermeiro ("posso cuidar") e o paciente ("preciso ser cuidado") no momento da sua internação, gerando conflitos. Ambos vivenciam sentimentos de traição, injustiça e abandono, causando maior sofrimento e induzindo a elaboração mútua de mecanismos de defesa frente a essa situação ${ }^{(8)}$. Além disso, segundo estudos, os enfermeiros utilizam mecanismos de defesa (fragmentação do relacionamento enfermeiro-paciente, despersonalização, categorização, negação da importância do indivíduo e racionalização de sentimentos) para se proteger do sofrimento psíquico inerente à natureza do processo de trabalho e da dominação exercida pelos representantes do poder institucional (médicos, instâncias deliberativas, normas). Tais mecanismos de defesa culminam em uma prática que pode estar muito distante de atitudes solidárias, de reconhecimento do sofrimento, de uma postura ético-humanística ${ }^{(9-11)}$.

Como o fulcro da situação de ansiedade para o enfermeiro reside em sua relação com o paciente, para evitá-la restringe seu contato com ele, passando a vê-lo não como pessoa, mas como alvo de tarefas que devem ser executadas. O enfermeiro torna-se um mero aglomerado de técnicas de enfermagem. Isso o impede de entrar efetivamente em contato com a totalidade de cada indivíduo e sua doença, enquanto lhe oferece alguma proteção contra a ansiedade que esse contato gera ${ }^{(9)}$. Dessa maneira, a lógica do tratamento e da administração do conforto pode fazê-la colidir com a meta de proporcioná-lo.

Vimos que no primeiro período (1900-1929) da literatura clínica norte-americana estudada ${ }^{(1)}$, a enfermeira era considerada a provedora de conforto físico, e, indiretamente, emocional. Atividades como usar travesseiros, acomodar o paciente e prover sua higiene caracterizam-se pela prestação de serviços e assistência pessoal ao outro. Nesse período, o conforto físico não implicava o uso de tecnologia, mas pressupunha a habilidade da enfermeira em tornar os pacientes confortáveis e a relação interpessoal, ainda que pobre em trocas intersubjetivas.

No segundo e terceiro períodos, o que se passa a exigir do enfermeiro são habilidades técnicas, de compreensão dos equipamentos e de interpretação do quadro de sinais e sintomas, a ponto de torná-la uma ótima informante do médico. O conforto físico é mediado pela tecnologia e, desse modo, a atenção do enfermeiro se volta para os equipamentos. Isso, somado, entre outros fatores, à divisão técnica do trabalho e ao desvio das funções do papel do enfermeiro determinam seu afastamento do paciente. Conseqüentemente, o trato direto com o paciente fica relegado ao pessoal auxiliar e o enfermeiro se torna uma espécie de gerente da assistência de enfermagem e, até certo ponto, da organização hospitalar, assumindo o controle administrativo de seu trabalho, como ocorre nos dias atuais.

Assim, a privação das trocas intersubjetivas não é característica apenas do período inicial. Ela se perpetua ao longo dos períodos seguintes, chegando até nossos dias. No entanto, as razões para tanto foram diferentes ao longo do tempo. No primeiro período reconhece-se a existência de uma desigualdade entre aqueles que prestam serviços e os pacientes. Tal desigualdade não se limita à questão econômica: existe também uma diferença social e cultural. Os ambientes em que as interações ocorrem também dificultam as trocas intersubjetivas. A enfermeira que atendia em domicílio ingressava na intimidade do paciente, e, apesar de ter acesso a seu corpo, não conseguia estabelecer uma relação sentimental e simbólica. Por outro lado, o hospital é uma instituição bastante familiar ao enfermeiro, mas não ao paciente, o que também dificulta as relações interpessoais.

$\mathrm{Na}$ atualidade, apesar das diferenças culturais e sociais entre enfermeiros e pacientes terem sido minimizadas, propiciando a aproximação destas à subjetividade dos pacientes, o distanciamento pessoal continua. Este é agora causado, dentre outros fatores, pela lógica científica da racionalidade funcional do hospital-empresa, que exige a prestação de serviços em larga escala e em alta velocidade, segundo uma nova concepção de conforto. Não se pode perder ainda a perspectiva das características inerentes ao processo de trabalho da enfermagem, que reforçam a fragmentação das relações interpessoais e, como vimos, induzem ao desenvolvimento de mecanismos de defesa.

Como vimos, há dois enfoques bem definidos do conforto na prática da enfermagem. No primeiro e mais antigo, as enfermeiras, sob influência religiosa, mas agindo independentemente das práticas médicas, eram as únicas administradoras e provedoras de conforto. Suas atividades eram exercidas principalmente nas instituições de caridade e visavam primordialmente o conforto da alma do paciente. Mais tardiamente, atuando no domicílio do paciente, em esfera mais laica, ainda mantinham autonomia na provisão do conforto, a qual gradualmente foi sendo subordinada à racionalidade médico-científica e às exigências políticas e econômicas institucionais.

Essa nova concepção de conforto ditada pela instituição hospitalar tem legitimidade operacional, racional e econômica. A racionalidade hospitalar que hoje vivemos é herança da ordem militar dos primórdios do capitalismo - quando tanto a enfer- 
magem quanto o paciente já estavam sujeitos à racionalidade médica e à ordem administrativa hospitalar ${ }^{\mathrm{b}}$. Se, no período inicial da história da enfermagem, o conforto era um imperativo moral de quem o praticava, a realização desse imperativo em ações cotidianas foi marginalizada pela institucionalização das práticas de saúde e seus desdobramentos.

Na atualidade, a racionalidade médica diferencia-se e subordina-se cada vez mais à ordem tecnológicoadministrativa hospitalar, que dita as políticas de atendimento à saúde segundo a lógica de mercado. Assim, o território hospitalar não pertence apenas aos profissionais de saúde, mas também aos interesses da em-

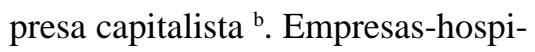
tais competem entre si anunciando seus serviços de hotelaria, deixando entrever o que consideram conforto; algumas expressam mesmo a idéia de promover conforto levando a família do paciente para o âmbito hospitalar, para minimizar os efeitos da ruptura com o cotidiano.

O conforto oferecido pelas instituições médico-hospitalares privadas é uma "mercadoria" que tem seu consumo determinado pelas leis de mercado e cujo acesso é proporcional ao poder aquisitivo de seus consumidores. O conforto de quem usufrui de um flat privativo, com acompanhamento familiar, apoio técnico e equipe médica ultra-especializada, é resultado de um serviço altamente elitizado que, além de confortar seus usuários, visa, em primeira instância, trazer um alto retorno financeiro a seus ofertantes. Vemos, portanto, que a concepção de conforto é determinada pela racionalidade administrativa hospitalar ${ }^{\mathrm{b}}$.

\footnotetext{
${ }^{b}$ Professor colaborador dos programas de estudos de Pós-Graduação (mestrado e doutorado) em Psicologia Social da PUC-SP - Pontifícia Universidade Católica de São Paulo, integrante do NEXIN Núcleo de Estudos Psicossociais da Dialética Exclusão/Inclusão Social da PUC-SP.
}

No entanto, o serviço médicohospitalar, enquanto mercadoria, atingiu um grau de sofisticação e elitização que faz com que poucos possam usufruir da plenitude de suas possibilidades humanas e tecnológicas. O sistema privado de saúde só é acessível a uma pequena parcela da população, cuja maioria tem de recorrer às versões mais básicas - e módicas - desses serviços, no sistema público. Vemos, assim, que as definições de conforto também podem carregar um viés social.

Nas instituições públicas de saúde, também inseridas na lógica macro-econômica neoliberal e vítimas do desmantelamento sistemático do Estado de Bem-Estar Social (por meio de otimização de recursos, “enxugamento da máquina”, “flexibilização do trabalho" e várias outras medidas que devem redundar em aumento de receitas), temos os consumidores de uma "versão popular" de conforto. Estes recebem um nível de conforto limitado pela decadência e abandono em que se encontram muitas dessas instituições: o péssimo aparelhamento técnico, recursos humanos subdimensionados para as colossais tarefas a serem cumpridas e as demais limitações materiais e humanas. Subverte-se, mais uma vez, a perspectiva que deveria nortear toda e qualquer atividade voltada à saúde: o bem-estar do ser humano.

Poderíamos exemplificar diferentes ordens administrativas racionais que ditam modelos de conforto, atreladas às classes sociais de consumidores específicos. Pensar em conforto por essa ótica seria concebê-lo como mercadoria a ser consumida. Embora se possa dizer que existam consumidores para tais serviços, não podemos afirmar que os sentidos de conforto para eles se assentam nos padrões "vendidos" pelo hospitalempresa. O conforto não deverá ser determinado por tal racionalidade. É preciso deslocar o foco do conforto da ótica institucional para a pessoal.
Seu sentido fundamental deverá ser compreendido na perspectiva do cidadão comum, que necessita dos serviços de saúde.

Embora a preocupação com o conforto seja histórica, sua concepção tem sido predominantemente evocada a partir do referencial do enfermeiro, da racionalidade científica e da administração hospitalar, pouco levando em consideração a relação do indivíduo com a doença e as práticas de saúde.

Vale ainda salientar que diante das dúvidas e imprecisões teóricas sobre conforto/cuidado (aparecem como sinônimos, ora conforto é componente do constructo cuidado ora cuidado é componente do constructo conforto; existem definições imprecisas ou idealizadas de conforto), entre outros fatores, vemos uma tendência da prática da enfermagem de se adequar, cada vez mais, a moldes e a demandas de tarefas advindos da instituição médico-hospitalar que, em geral, focalizam o enfermeiro basicamente como gerenciador de ações técnicas e responsável pela prestação de um acúmulo de serviços, eximindo-o de, ou dificultando, qualquer relação intersubjetiva com o paciente. Na lógica técnico-hospitalar, o cuidar ou confortar consiste basicamente na realização de procedimentos, no controle dos processos de tratamento, controle de tempos e movimentos e do ambiente hospitalar ${ }^{(2)}$.

Se a prática da enfermagem se assenta em lógicas de atuação que a afastam das trocas intersubjetivas, não é difícil admitir que o paciente é concebido como um corpo-máquina, que requer intervenção para o conserto de sua avaria. O enfermeiro, por sua vez, é um instrumento que intervém para ajudar a recuperar esse corpo e realizar a finalidade de legitimação da instituição. Nessa perspectiva, conforto é unidimensional e a racionalidade que o produz é instrumental, porque reduz o paciente a um corpo e o enfermeiro a um instrumento, capaz de justifi- 
car e manter a própria lógica institucional. Nesse sentido, as ações do enfermeiro podem não supor o indivíduo ativo, sua sensibilidade, cultura, moralidade, intimidade. A ação pode ser regida por uma lógica técnico-científica sem, necessariamente, incluir considerações de ordem ética, quando o uso do conhecimento técnico-científico prescinde das relações humanas, onde o paciente deixa de ser reconhecido como pessoa e passa a ser visto como um quadro patológico. Assim, nessa perspectiva, gerar conforto permanece no nível do discurso normativo; o enfermeiro pode, ou não, adotá-lo como imperativo moral: e, mesmo que o adote, não consegue, freqüentemente alcançá-lo na prática.

Hoje, a prática da enfermagem é regida por uma razão técnico-científica legitimada por um discurso conceitual cujo alicerce é o modelo biomédico. No mundo moderno, regido pela ciência, a enfermagem para se legitimar como profissão, em instituições científicas, adota esse modelo.

Com a complexidade do conhecimento e ampliação da infra-estrutura institucional (no caso, o hospital e outros instrumentos necessários para possibilitar a realização do modelo clínico), outros trabalhadores vão se agregando a esse que passa a ser um trabalho coletivo [...] A enfermagem, portanto, nesse modelo clínico de saúde, é parte desse processo, é parte do trabalho médico; sua ação é um instrumento que cuidará ou fará cuidar do corpo doente [...] Assim, o trabalho de enfermagem, no modelo de saúde individual, que é o clínico, passa a ser um instrumento ou meio do processo de trabalho médico(4).

Aqui, manifestam-se nítidas contradições entre a exigência ética de promover o conforto do paciente e a prática médica baseada no modelo biomédico, o que resulta numa abordagem terapêutica centrada na disfunção em si, freqüentemente perdendo de vista o paciente como ser humano. Contribuem para a visão fragmentada do paciente a especialização da medicina, quando reduz os sujeitos a mecanismos celulares e moleculares, e o uso crescente de tecnologias que, pela relação estabelecida, pode afastar o paciente dos profissionais e se constituir em fontes de acréscimo de sofrimento.

Sem dúvida, é relevante o desenvolvimento atingido pela ciência no que se refere às tecnologias que oferecem suporte vital, ampliam as possibilidades diagnósticas e terapêuticas. Todavia, parece desproporcional nesse quadro o papel do paciente como pessoa ativa, capaz de participar das questões referentes a sua própria saúde, capaz de escolher, decidir e direcionar a própria existência de acordo com a significação que a ela atribui. A despeito de todas as contribuições e reflexões trazidas pela bioética, não é difícil constatar a despersonalização do atendimento prestado nos hospitais, o cuidado e tratamento centrados meramente na tecnicidade e cientificidade, a negação da importância da subjetividade e a racionalização de sentimentos.

Na prática, é possível constatar, também, a inexistência de pessoal preparado e de recursos materiais para a qualificação do atendimento e, em situações mais extremas, da negação do direito à saúde, pela insuficiência de benefícios oferecidos pelos serviços de saúde. Aqui, reiteramos a questão: Quem são, para nós enfermeiros, os sujeitos de nossas interações? De que modo o avanço técnico-científico contribui para aliviar o desconforto produzido pela ameaça à vida?

A lógica e a força do sistema hospitalar é tão grande e eficaz que faz com que as próprias instituições de ensino de Enfermagem assumam, sem muita crítica, o conforto como imperativo moral, que é explicitado do ponto de vista teórico a partir de uma visão humanista. Durante minha atuação no ensino de Graduação em Enfermagem, nos últimos nove anos, percebo que os professores se esforçam em transmitir aos alunos uma noção de cuidado/ conforto solidária, afetuosa e humana. Muito embora as instituições de ensino de Enfermagem enfatizem esse enfoque na formação, os novos enfermeiros, ao ingressar no mercado de trabalho, precisam se ajustar à "política do cuidado/conforto" ditada pelos interesses de seus empregadores. Muitas vezes, na prática, o aluno tem de se adequar às regras da instituição hospitalar e, embora imbuído de conteúdos humanistas, ao se inserir no cotidiano das instituições hospitalares vive a dicotomia entre o que é ensinado e as demandas de atividades que lhe são requeridas. Ao pactuar com essa política institucional, independente de sua vontade, os enfermeiros também são coisificados e, assim, sofrem pela angústia e impotência de não conseguir transformar em ações cotidianas o imperativo moral da profissão.

Também é verdade que a formação do enfermeiro (currículo, literatura, práticas etc.) é repleta de conteúdos que lhe prescrevem atitudes altruístas e responsabilidades morais que, muitas vezes, representam um fardo pesado demais para sua condição humana. Imperativos morais do tipo: "a missão da enfermagem é cuidar da vida” não são incomuns no discurso da Enfermagem. Ora, cada ser humano tem a responsabilidade de cuidar de sua própria vida. Assim, a dicotomia "conforto no ensino" versus "conforto na prática institucional” gera conflitos para o enfermeiro e prejudica a compreensão dos fatores que, na ótica do paciente, produzem conforto/desconforto. Embora a literatura de enfermagem pouco responda sobre o que produz conforto/desconforto na ótica dos pacientes, é 
ela que ainda norteia a formação e a prática da enfermagem e que serve de critério para avaliar a qualidade de um bom enfermeiro ou curso de formação. Segundo essa literatura, a função fundamental do enfermeiro é a promoção do conforto, razão pela qual precisamos conhecer os determinantes desses fenômenos na perspectiva dos sujeitos que o experimentam e de sua interação com as práticas dos profissionais que o proporcionam.

\section{CONSIDERAÇÕES FINAIS}

Na perspectiva teórica neste estudo defendida, conforto/desconforto devem ser tratados como estados subjetivos e, como tal, somente podem ser entendidos à luz das interações vivenciadas pelo paciente e, portanto, vinculadas aos fatores objetivos das instituições e da racionalidade e práticas que as fundam. Tratar o conforto como um estado subjetivo implica centrar o foco na interação dos profissionais de saúde com o indivíduo, um ser de relações e de possibilidades; implica res- gatar o humano, rompendo e extrapolando as concepções que reduzem o indivíduo a paciente, buscando incorporar outras lógicas no atendimento que tragam à tona, no interior do hospital, a vida do sujeito.

\section{REFERÊNCIAS}

1. McIlveenn KH, Morse J. The role of comfort in nursing care: 1900-1980. Clin Nurs Res 1995; 4(3):127-48.

2. Mussi FC. Padecendo a perda da espontaneidade da ação: o desconforto vivenciado por homens que sofreram infarto agudo do miocárdio. [tese doutorado]. São Paulo: Escola de Enfermagem da USP; 2000.

3. Dolan JA. Nursing in society: a historical perspective. 15th ed. Philadelphia: Saunders; 1983.

4. Almeida MCP, Rocha JSY. O saber de enfermagem e sua dimensão prática. São Paulo: Cortez; 1986.

5. Foucault M. Incorporación del hospital en la tecnologia moderna. In: Organização Panamericana de Saúde. Medicina e história: el pensamiento de Michel Foucault. Washington: OPS/OMS; 1978. p. 59-74.
6. Melo C. Divisão social do trabalho e enfermagem. São Paulo: Cortez;1986.

7. Nursing Development Conference Group. Concept formalization in nursing: process and product.2nd ed. Boston: Little Brown; 1973.

8. Wagner D. The proletariarization of nursing in the United States 1932-1946. Int J Health Serv 1980; 10(2):271-91.

9. Ide CAC. O ensino superior em enfermagem: o núcleo de significações para a expressão de uma nova ação pedagógica. [tese livre-docência]. São Paulo: Escola de Enfermagem da USP; 1995.

10. Menzies I. O funcionamento das instituições como sistemas sociais de defesa contra a ansiedade. São Paulo: Escola de Administração de Empresas da FGV; s.d./mimeo/

11. Tassara ETO, Damergian S. Para um novo humanismo: contribuições da Psicologia Social. Rev Est Avançados 1996; 10(28):291-316.
Mussi FC. [Comfort and hospital practice: an analysis from the historical perspective of the concept of confort in nursing.] Acta Paul Enferm 2005; 18(1):72-81.

ABSTRACT: Analysis of nursing literature from the beginning of the nursing practice until now shows that comfort is viewed as the aim of nursing care and that it is also regarded as a critical concept in the history of nursing. Therefore, this study was undertaken in order to analyse the theoretical concepts of comfort during the nursing history as well as its defining factors in an attempt to clarify the meaning of comfort as a theoretical concept and its impact in nowadays practice and teaching of nursing.

Descriptors: Nurses'role; Nursing care; History of nursin
Mussi FC. [Conforto y lógica hospitalaria: una análisis a partir de la evolución histórica del concepto conforto en la enfermería.] Acta Paul Enferm 2005; 18(1):72-81.

RESUMEN: El análisis de la literatura de enfermería evidencia que, desde el princípio de la profesión hasta nuestros dias, el conforto es una meta del cuidado y un concepto presente en toda su historia. Siendo así,este estúdio analisa concepciones teóricas sobre el conforto en la historia de la enfermería y sus determinantes, con la intención de encontrar pistas que permitan esclarecer las impresiciones teóricas existentes sobre el conforto y en las contradicciones vividas en la práctica y en la enseñanza de la enfermería en lo que respecta a la promoción del conforto.

Descriptores: Rol de la enfermera; Atención de enfermería; Historia de la enfermería 